\title{
Thymoma Epithelial Cells Secrete Thymic Hormone but Do Not Express Class II Antigens of the Major Histocompatibility Complex
}

\author{
Wilson Savino, Geri Manganella, Jeanne-Marie Verley, Annie Wolff, Sonia Berrih, Philippe Levasseur, Jean-Paul Binet, \\ Mireille Dardenne, and Jean-François Bach \\ INSERM, Hôpital Necker, 75730 Paris, Cédex 15, France
}

\begin{abstract}
17 thymomas were studied by indirect immunofluorescence for the presence of thymic hormones and antigens of the major histocompatibility complex (MHC). The thymoma epithelial cells (specifically identified by their keratin content) contained thymic hormones (thymulin and thymosin $\alpha 1$ ), a finding corroborated by the observation of elevated thymulin serum levels. In contrast with normal or hyperplastic thymuses, thymoma epithelial cells did not express HLA-DR and HLA-DC antigens as assessed by immunofluorescence as well as immunoblot analyses. Conversely, MHC class I antigens (HLA-ABC) were normally expressed. Thus, we conclude that thymoma epithelial cells are endocrinologically active but are defective for the expression of some MHC products (class II molecules) known to play an essential role in intrathymic $\mathbf{T}$ cell differentiation.
\end{abstract}

\section{Introduction}

Thymomas may be defined as the uncontrolled proliferation of thymic epithelial cells, regardless of the presence or absence of the lymphoid component (1). Although variable amounts of lymphoid cells can be found in thymomas, the neoplastic proliferation is restricted to the epithelial component of the thymus. The tumor is frequently benign, particularly in older patients, but signs of local invasion are not uncommon, and in some cases true lymphatic or hematogenous spread may exist and generate metastases (1). The thymoma is often clinically silent. However, it may also be associated with a number of diseases, among which the most common is myasthenia gravis (MG). ${ }^{1}$ In fact, $\sim 10 \%$ of myasthenics have thymoma (2).

To date, studies of epithelial cells in thymomas have mainly focused on the morphology of the tumor. A classification has been proposed, as a function of morphological criteria defined by light and electron microscopy (2-4). More recently, the use of antikeratin antibodies provided a new tool in the study of

\footnotetext{
Address correspondence to Dr. Dardenne. 1985.

Received for publication 5 April 1984 and in revised form 5 February
}

1. Abbreviations used in this paper: FCS, fetal calf serum; GAM/FITC, goat anti-mouse immunoglobulins coupled to FITC; GAMIgG2b/FITC, goat anti-mouse IgG2b immunoglobulin fraction conjugated to FITC; GAM/TRITC, goat anti-mouse immunoglobulins coupled to TRITC; GAR/FITC, goat anti-rabbit immunoglobulins conjugated to fluorescein isothiocyanate; GAR/TRITC, goat anti-rabbit immunoglobulins conjugated to tetramethylrhodamine isothiocyanate; IF, immunofluorescence; MAb, monoclonal antibody; MG, myasthenia gravis; MHC, major histocompatibility complex; NC, nitrocellulose.

\footnotetext{
J. Clin. Invest.

(c) The American Society for Clinical Investigation, Inc.

0021-9738/85/09/1140/07 \$1.00

Volume 76, September 1985, 1140-1146
}

thymomas by allowing an easy distinction to be made between thymic epithelial cells and other cell types. These antibodies label the cytokeratin-containing intermediate filaments, which in the thymus are restricted to the epithelial component (5). These keratin filaments were proved to be consistently present in all cases of thymomas so far studied (6); hence the use of antikeratin antibodies in several laboratories as a probe for the differential diagnosis between thymoma and lymphoma of the thymus.

Little data are available, however, on the functional capacity of tumoral epithelial cells, particularly for the production of thymic hormones known to play an important role in $\mathrm{T}$ cell differentiation (7). Three of these hormones have now been wellcharacterized, both chemically and biologically; namely, thymulin (formerly called FTS for Facteur Thymique Sérique), thymosin $\alpha 1$, and thymopoietin (8-10). The localization of these peptides within the thymus has been achieved by means of immunofluorescence (IF). Thymulin (11-13), thymosin $\alpha 1$ (14, $15)$, and thymopoietin $(16,17)$ are found exclusively in the epithelial cells of the thymus, and immunoelectron microscopic studies have shown that thymulin is actually localized within cytoplasmic vesicles; results were obtained with both polyclonal $(18,19)$ and monoclonal $(20)$ antithymulin antibodies.

Another important function of the thymus, usually attributed to thymic epithelial cells, is the presentation of products encoded by the major histocompatibility complex (MHC) to immature lymphocytes, a phenomenon believed to be of paramount importance in the acquisition of the self-recognizing reactivity of $T$ cells. Studies in mice $(21,22)$ and in humans $(23)$ on the localization of $\mathrm{MHC}$ products in the thymus have shown that these antigens are essentially located in the plasma membrane of epithelial cells.

We have studied the distribution of the functional markers of epithelial cells, thymic hormones, and MHC products in a series of thymomas (associated or not with MG) compared with nonthymomatous myasthenic thymuses and normal human thymuses. Furthermore, the immunohistological distribution of thymulin has been correlated with its serum level, assessed by a previously described rosette bioassay.

\section{Methods}

Patients. 17 patients with thymoma (age ranging from 33 to $69 \mathrm{yr}$ ) were included in the study. Among them, 11 had MG. Prethymectomy total lymphocyte blood counts, as well as $T$ cell subset distribution analyzed by OKT 3, OKT 4 , and OKT 8 antibodies, were within the normal ranges $\left(\mathrm{OKT}^{+} / \mathrm{OKT}^{+}=1.3\right)$. The number and/or proportion of Ig-bearing cells (B lymphocytes) was also normal. Among 15 patients tested, 14 bore circulating antiacetylcholine receptor antibodies. Histopathologically, according to Verley and Hollmann's classification (4), the present series was comprised of 5 benign ( 2 spindle cell and 3 lymphocyte-rich thymomas) and 12 malignant cases ( 9 were of the differentiated epithelial type and 3 were described as undifferentiated epithelial thymomas).

As immunohistological controls, 10 nonthymomatous thymuses (with variable amounts of lymphoid follicles) were obtained from myasthenic 
individuals (aged from 20 to $42 \mathrm{yr}$ old) and 8 thymuses from normal children or adolescents. Four thymuses from normal adults (aged from 32 to $63 \mathrm{yr}$ old) were also studied.

\section{Materials}

Reagents. Hank's medium and sheep erythrocytes were obtained from the Pasteur Institute (Paris, France). Azathioprine, used in its sodium salt form, was obtained from Burroughs Wellcome \& Co., Greenville, NC. Thymulin (FTS-Zn) was synthesized by P. Lefrancier, Choay, France. Synthetic thymosin $\alpha 1$ was kindly provided by Dr. C. Stähli (Hofman La Roche Institute, Basel).

Specific antibodies. An antikeratin xenoantiserum was purchased from Clinisciences (Sées, France) and used at the dilution of 1:50. An antikeratin monoclonal antibody (MAb) that recognizes an epitope common to different cytokeratins was a gift from Dr. Jean Brochier (INSERM, Lyon, France) (24). It was used in its unpurified form (culture supernatant diluted 1:20). Three different anti-HLA-DR MAb were used. The monoclonal 7.2 (25) was purchased from New England Nuclear, Boston, MA. It is an IgG2b immunoglobulin used as an ascitic fluid diluted 1:10. The antibody LKT 111 (26) was a gift from R. Bono (Pasteur Institute). It is an IgM used as an ascitic fluid diluted 1:80. The third anti-HLA-DR MAb, L243 (27), obtained from Becton-Dickinson \& Co., Oxnard, CA, is an IgG2a whose ascitic fluid was used at the dilution 1:100. These three monomorphic anti-HLA-DR MAb were shown to precipitate both heavy and light chains of the DR complex. The antiHLA-DC MAb is the clone Leu-10 from Becton-Dickinson \& Co. It is an IgGl shown to recognize DC molecules of the $\operatorname{MHC}(28,29)$. The anti-HLA-ABC MAb B1.23.2 and M18 were gifts respectively from Dr. B. Malissen (30) and Dr. M. Fellous (31). B1.23.2 precipitates a 45-kD protein of the HLA-class I complex, whereas M18 recognizes an epitope of the $\beta 2$-microglobulin. Ascitic fluids were used at a dilution of 1:400. The anti-thymosin $\alpha 1$ xenoantiserum, a gift from A. L. Goldstein (George Washington University, Washington, DC), was raised in rabbits immunized with synthetic thymosin $\alpha 1$ coupled to keyhole limpet hemocyanin. The specificity of this antiserum was demonstrated by radioimmunoassay (32) and IF (13). In the present study it was used diluted 1:10. The antithymulin MAb was prepared in C57BL/6 mice immunized with cultured human thymic epithelial cells. The antibody produced was lgG2b and its specificity for natural as well as synthetic thymulin has already been demonstrated (33). The ascitic fluid used in these experiments was diluted 1:20, which represents an immunoglobulin concentration of $0.1 \mathrm{mg} / \mathrm{ml}$.

Fluorescent conjugates. All the fluorescent conjugates were purchased from Nordic Laboratories (Tilburg, The Netherlands) and were systematically preabsorbed with rat organ powder to avoid nonspecific fluorescence. The goat anti-rabbit immunoglobulins conjugated to fluorescein isothiocyanate (GAR/FITC) or tetramethylrhodamine isothiocyanate (GAR/TRITC) were used at dilutions of 1:50. The goat anti-mouse immunoglobulins coupled to TRITC (GAM/TRITC) and FITC (GAM/ FITC) were diluted 1:50; the goat anti-mouse IgG2b immunoglobulin fraction conjugated to FITC (GAMIgG2b/FITC) as well as the GAMIgG2a/FITC and the GAMIgG1/FITC were used at dilutions of $1: 20$.

\section{IF studies}

Thymic fragments were frozen in liquid nitrogen a few minutes after surgical removal. At least two different fragments from each patient were analyzed. In all IF studies, $2-\mu \mathrm{m}$ unfixed thick frozen sections were treated as previously described $(12,13)$. When double labeling experiments were performed, the frozen sections were sequentially incubated with the first specific antibody and its proper fluorescent conjugate followed by the second specific antibody and its corresponding conjugate.

Several markers were investigated by the indirect IF assay. They included two thymic hormones, namely, thymosin $\alpha 1$ and thymulin, keratin, HLA-ABC, HLA-DR, and HLA-DC molecules. Thymulin was detected using the antithymulin MAb revealed by the GAMIgG2b/FITC; thymosin $\alpha 1$, by the antithymosin $\alpha 1$ xenoantiserum revealed by the
GAR/FITC. Thymic cytokeratins were detected either by the antikeratin antiserum (revealed by GAR/TRITC) or by the MAb (revealed by the GAM/TRITC). For the detection of HLA-ABC antigens, the anti-HLA$A B C$ MAb revealed by the GAMIgG2a/FITC was used. The binding of the anti-HLA-DR was revealed by the GAMIgG2b/FITC, GAM/FITC, or GAMIgG2a/FITC (according to their respective subclasses), and the anti-HLA-DC MAb was revealed with the GAMIgG1/FITC.

\section{Immunoblot analysis}

Fragments of two normal human thymuses and four thymomas were put in a buffer solution containing $0.1 \mathrm{M} 2(\mathrm{~N}$-morpholino) ethane sulphonic acid, pH 6.4, $1 \mathrm{mM}$ EGTA, $0.5 \mathrm{mM} \mathrm{MgCl}, 0.1 \mathrm{mM}$ EDTA, 1 $\mathrm{mM}$ GTP, and $1 \mathrm{mM}$ mercaptoethanol, and then homogenized. The total tissue extract obtained was mixed with the sample buffer solution containing $0.32 \%$ dithiothreitol, $0.5 \%$ sodium dodecyl sulphate (SDS), $0.2 \mathrm{M}$ Tris, $\mathrm{pH} 6.8,0.25 \%$ glycerol, and $0.01 \%$ bromophenol blue. After being boiled at $100^{\circ} \mathrm{C}$ for $3 \mathrm{~min}$ the preparations were used for electrophoresis.

Electrophoresis was carried out in a discontinuous slab gel containing $0.1 \%$ SDS composed of a $5-\mathrm{cm}$ long stacking gel (5\% acrylamide, $0.13 \%$ bisacrylamide) and a $24-\mathrm{cm}$ long separating gel (12\% acrylamide, $0.32 \%$ bisacrylamide) following the technique initially described by Laemmli (34). The electrophoresis was run overnight at $11 \mathrm{~mA} / \mathrm{gel}$.

For immunological detection, proteins separated by gel electrophoresis were transferred onto nitrocellulose (NC) sheets $(0.45 \mathrm{~m}$; Millipore/Continental Water Systems, Bedford, MA) after a $2 \mathrm{~h}$ and $30 \mathrm{~min}$ electrophoresis at $250 \mathrm{~mA}$ in $25 \mathrm{mM}$ Tris, $1.92 \mathrm{mM}$ glycine, $\mathrm{pH} 8.3$, and $20 \%$ (vol/vol) methanol buffer. Proteins on NC were stained with $0.2 \%$ Ponceau red in 3\% trichloracetic acid. The NC sheets were saturated for 1 $\mathrm{h}$ at room temperature with $10 \%$ fetal calf serum (FCS) in phosphatebuffered saline (PBS). After being washed with $10 \%$ FCS and $0.2 \%$ NP40 in PBS, the NC sheets were incubated $18 \mathrm{~h}$ at $4^{\circ} \mathrm{C}$ with the MAb L 243 (anti-HLA-DR) and Leu 10 (anti-HLA-DC), both diluted 1:10.

After several washings with $10 \%$ FCS and $0.2 \%$ NP40 in PBS, NC sheets were incubated with peroxidase conjugate goat Ig antibodies against mouse immunoglobulins (Amersham Int., Amersham, Buckinghamshire, England) for $2 \mathrm{~h}$ at room temperature. After the sheets were washed again, peroxidase activity was revealed with $0.03 \% \mathrm{H}_{2} \mathrm{O}_{2}$ in the presence

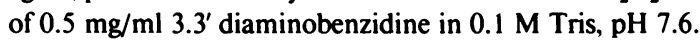

\section{Evaluation of thymulin levels in the peripheral blood}

The serum level of biologically active thymulin was evaluated by a rosette assay described in detail elsewhere (35), and shown by us and several other investigators to be strictly thymus-specific (36-38). To confirm the specificity of the biological activity measured, all the determinations were repeated after preincubation of the sera under study with an antithymulin MAb or a specific antithymulin immunoadsorbent.

\section{Results}

Epithelial (keratin-containing) network. Cytokeratin cytoplasmic filaments were observed in all thymuses studied and were used as a specific marker for epithelial cells. In the majority of thymomas, the epithelial (keratin-positive) network was strikingly dense compared with control thymuses. In some cases, small round cells predominated, but, in general, the epithelial cells presented many cytoplasmic processes. Hassall's corpuscles were seldom seen or totally absent.

Thymuses from MG patients, whether hyperplastic or involuted, showed an epithelial network pattern sharply different from that observed in thymomas. In both cases, the epithelial framework was usually roughly similar to that found in the normal thymus, with distinguishable cortical and medullary regions and many Hassall's corpuscles. In some hyperplastic thymuses, 
however, isolated clusters of small round epithelial cells displaying a denser pattern, similar to those observed in many thymomas, could be identified.

Thymic hormones. In most thymomas studied (associated or not with MG), the great majority of epithelial cells were doubly labeled with the antikeratin serum and very brightly labeled with the antithymulin monoclonal (Fig. 1). The specificity of this labeling for thymulin was confirmed by the complete inhibition of the fluorescence observed after preincubation of the antibody with synthetic thymulin $(100 \mu \mathrm{g} / \mathrm{ml})$.

Thymuses (hyperplastic or involuted) from nonthymomatous myasthenic patients also showed many thymulin-containing
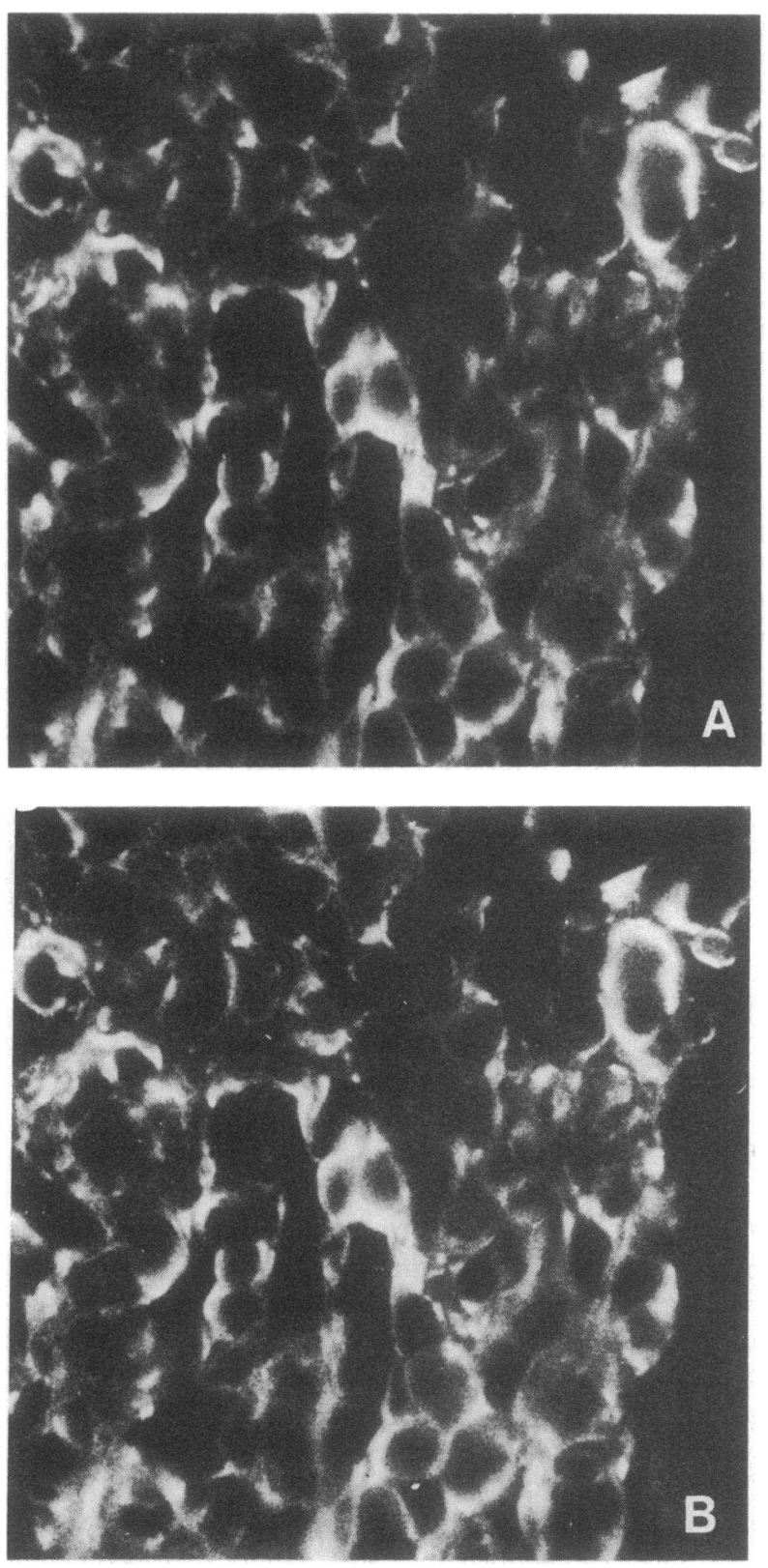

Figure 1. Thymoma frozen section immunolabeled by the antithymulin MAb (revealed by GAMIgG2b/FITC in Fig. $1 A$ ) and the antikeratin antiserum (revealed by the GAR/TRITC in Fig. $1 B$ ). Thymoma epithelial cells are very rich in thymulin. $\times 500$. cells in their parenchyma. These cells were found in the cortical as well as medullary regions of thymic lobules. In Hassall's corpuscles, the most peripheral cell layers were frequently (but not always) labeled.

Many thymosin $\alpha 1$-containing cells were also observed in the great majority of thymomas studied. Their strict epithelial nature was demonstrated by double labeling immunofluorescence experiments in which they were all stained by the antikeratin MAb. The specificity of the antithymosin $\alpha 1$ binding was confirmed by the complete fluorescence inhibition achieved when the antiserum was preincubated with synthetic thymosin $\alpha 1(100 \mu \mathrm{g} / \mathrm{ml})$. In the MG thymuses, either hyperplastic or involuted, similar results were observed, thus confirming the previous findings reported by Dalakas et al. (14). Furthermore, using sections double labeled by the antithymulin MAb and the antithymosin $\alpha 1$ serum, we found that the same cells bound both antibodies (Fig. 2). It should be noted that the possibility of cross-reaction between these two antibodies for one thymic hormone was discarded in view of the inability of thymulin to inhibit antithymosin $\alpha 1$ fluorescence and of thymosin $\alpha 1$ to prevent antithymulin labeling.

Lastly, it is worth noting that in two patients, differential diagnosis could not be made between thymoma and other undifferentiated mediastinal tumors by conventional histology and electron microscopy. The demonstration of the epithelial nature of the malignant cell by the antikeratin antibodies and the labeling of the antithymulin and antithymosin $\alpha 1$ antibodies permitted the determination of their thymic origin.

Thymulin serum levels. Abnormally high levels of circulating thymulin were observed in the great majority of the patients studied. Thus, in the case of thymomas (associated or not with MG) thymulin levels were an average of six times higher than those found for normal age-matched individuals (Fig. 3). Interestingly, patients showing the lowest thymulin levels also showed unusually low numbers of thymulin-containing cells in their tumors.

Nonthymomatous myasthenics (with hyperplastic or involuted thymuses) also showed significantly higher thymulin levels than normal subjects of the same age, thus confirming our previous studies in myasthenic patients (39). However, when compared with normal age-matched controls, significantly higher levels were measured in thymomatous patients than in myasthenic patients without thymoma.

The specificity of this hormonal activity was confirmed by its disappearance in all the cases after preincubation of the serum with a specific antithymulin immunoadsorbent or after evaluation of the same patient's serum after thymectomy.

$H L A-A B C$ antigens. Class I MHC antigens were consistently detected in thymoma epithelial (keratin-containing) cells (Fig. 4). Both anti-HLA-ABC MAb used strongly labeled these cells. In addition, lymphocytes and nonepithelial dendritic cells were also stained.

In hyperplastic or involuted MG thymuses, the distribution of HLA-ABC antigens was similar to that which we observed in the normal thymus. Medullary and cortical epithelial cells were sharply labeled but lymphocytes (including lymphoid follicles in the perivascular spaces of MG thymus) and nonepithelial dendritic cells were also consistently recognized by the monoclonals.

$H L A-D R$ and $H L A-D C$ antigens. Only very few thymoma cells were labeled by anti-HLA-DR MAb. These thymomatous 

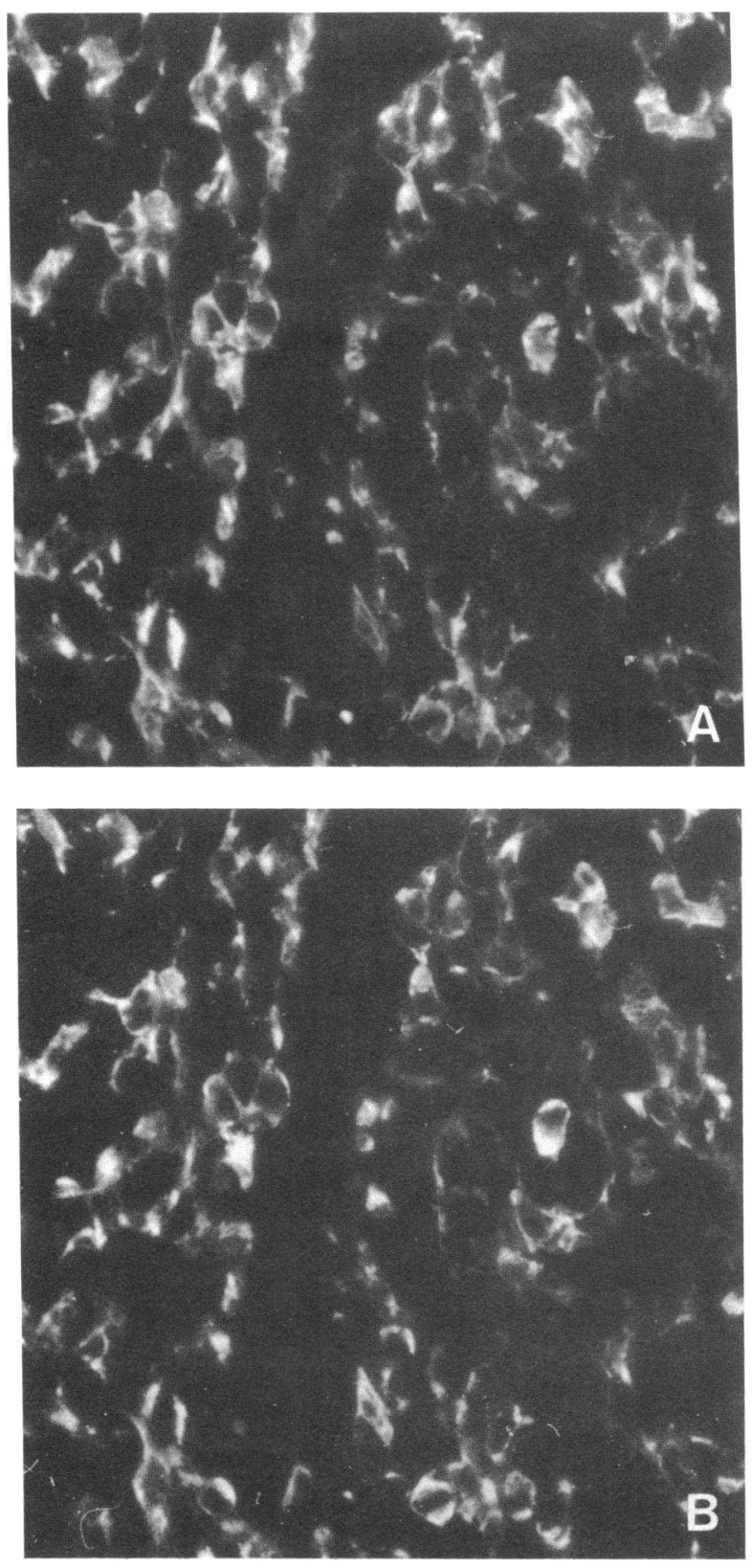

Figure 2. Thymoma frozen section double labeled with the antithymo$\sin \alpha 1$ antiserum (Fig. $2 A$ ) revealed by GAR/TRITC and with the antithymulin MAb (evidenced in $2 B$ ) by the GAMIgG2b/FITC). Epithelial cells are sharply labeled by both antithymic hormone antibodies. $\times 500$.

HLA-DR-positive cells were sparsely scattered throughout the organ and had a dendritic shape. The double labeling experiments using the anti-HLA-DR MAb and the antikeratin serum clearly showed that these HLA-DR-positive cells were keratinnegative and thus not epithelial (Fig. 5). Epithelial cells were consistently $\mathrm{DR}^{-}$. This pattern was observed in all thymomas with all anti-DR antibodies tested regardless of whether they were from myasthenic or nonmyasthenic patients. Quite similar results were also observed concerning the presence of HLA-DC molecules (data not shown).

This lack of class II molecules observed in IF on thymomatous epithelial cells was further confirmed with the immu-

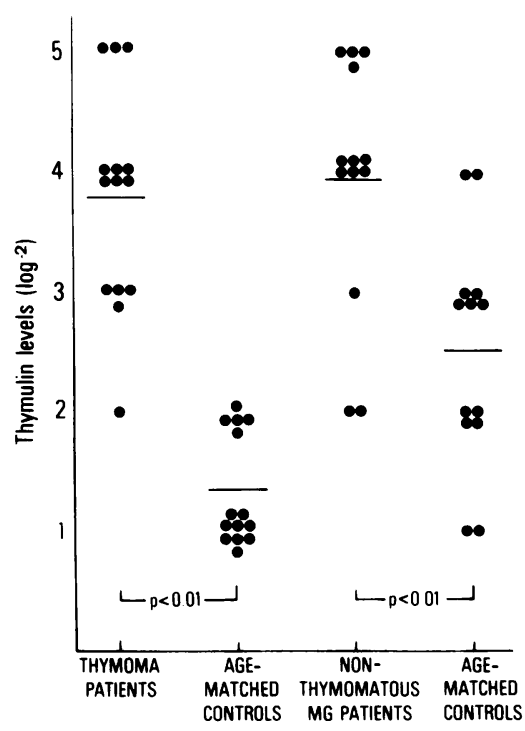

Figure 3. Thymulin levels in thymoma and nonthymomatous MG patients, as compared with aged-matched normal individuals. The use of two control groups is explained by the fact that nonthymomatous subjects were younger than those bearing thymoma. However, thymulin levels are significantly higher in both MG groups than in their respective age-matched controls. (Results are expressed as log-2 reciprocal titers.)

noblot analysis. Both polypeptide chains of DR and DC complexes were detected in extracts of normal thymuses but not in the four thymomas studied (Fig. 6). In contrast with thymomas, hyperplastic and involuted MG thymuses revealed a large proportion of epithelial cells bearing class II antigens in a pattern similar to that found in the normal thymus (Fig. 7). Both cortical and medullary epithelial cells were strongly labeled by the antiHLA-DR and anti-HLA-DC MAb. In addition, within the pe-

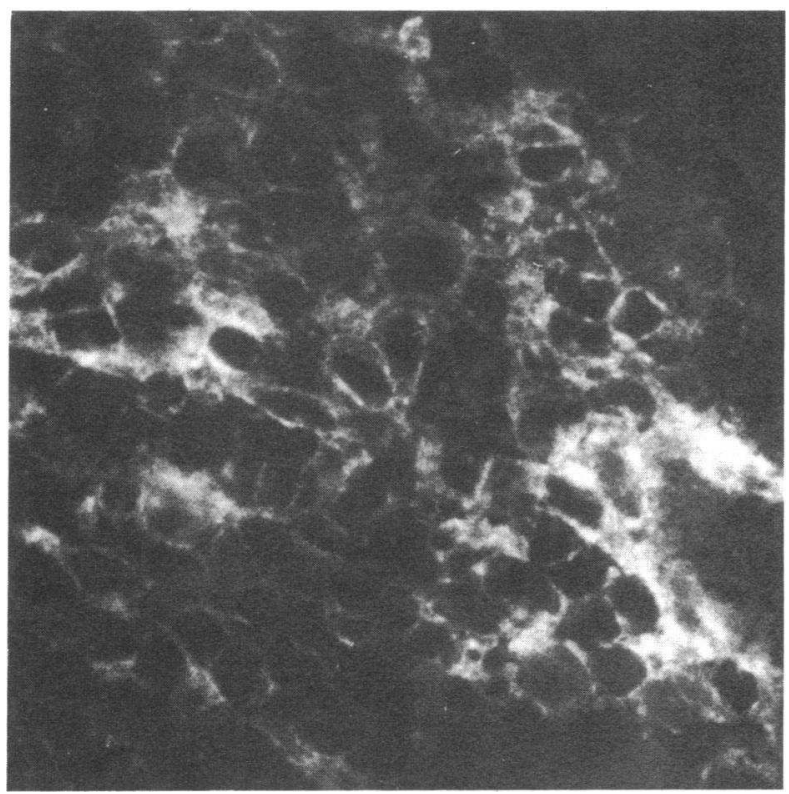

Figure 4. Thymoma frozen sections labeled with the anti-HLA-ABC MAb revealed by GAMIgG2a/FITC. HLA-ABC molecules are wellexpressed by thymoma epithelial cells. $\times 500$. 

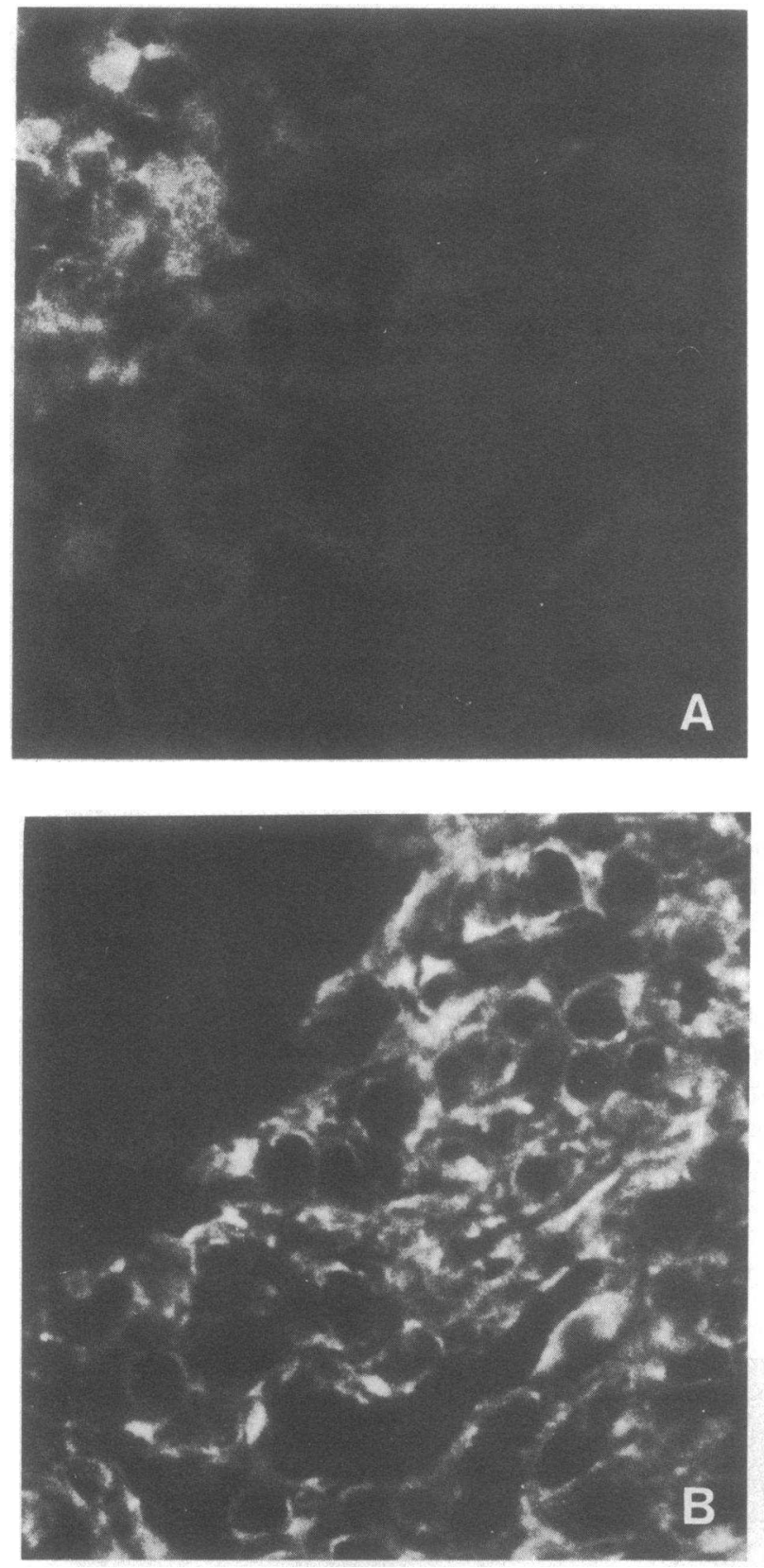

Figure 5. Thymoma frozen section immunolabeled by the anti-HLADR MAb (revealed by GAMIgG2b/FITC in Fig. $5 \mathrm{~A}$ ) and the antikeratin serum (revealed by GAR/FITC in Fig. $5 \mathrm{~B}$ ). The only HLA-DRpositive cells seen are not epithelial (keratin-containing) cells. $\times 500$.

ripheral epithelial cell layer of Hassall's corpuscles a strong labeling was noted. Nonepithelial dendritic cells from both hyperplastic and involuted thymuses were also HLA-DR and HLADC positive. These cells were predominantly localized in the connective tissue septae of the organ, but some of them were also observed within the parenchyma of the thymic lobules. Furthermore, in hyperplastic thymuses, several clusters of class II positive cells (probably B cells) were found in the thymic septae.

\section{Discussion}

This paper provides a functional approach to the study of thymomas, associated or not with MG. The first and major con-

\section{0}

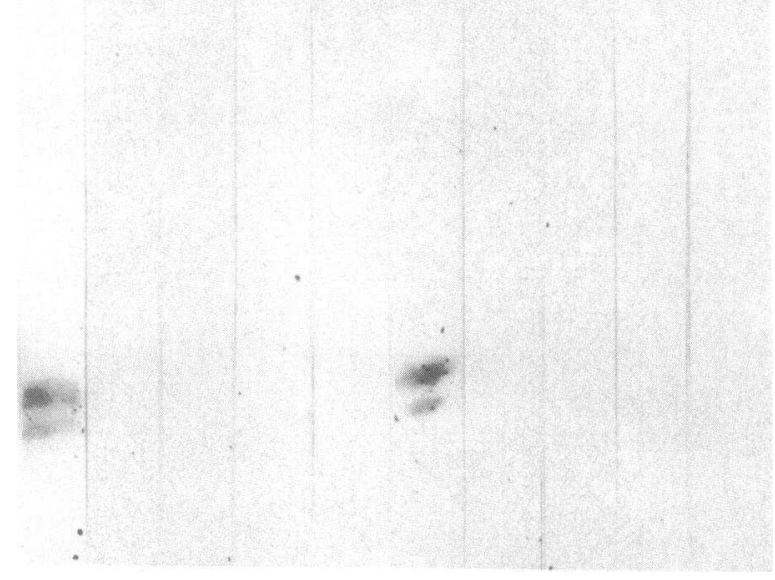

Figure 6. Immunoblot analysis using the anti-HLA-DR (lanes 1-5) and the anti-HLA-DC (lanes 6-10) monoclonal antibodies, on transferred proteins from a normal human thymus (lanes 1 and 6 ) and from four different thymomas (lanes 2-5 and 7-10). The two polypeptidic chains (29 and $33 \mathrm{kD}$ ) of DR and DC complexes were detected in the normal thymus but not in any of the thymomas.

clusion to be drawn from our studies is that in thymomas as well as in the several other pathological thymic conditions involving the epithelial component, which is either expanded as in thymic hyperplasias or atrophic as in the so-called "involuted" myasthenic thymus, thymic epithelial cells still produce thymic hormones (as revealed by IF). Furthermore, they secrete them, as shown by the abnormally high thymulin blood levels observed in the majority of the patients studied. Such studies have not yet been reported for any other thymic pathological conditions.

Our results are in keeping with previous findings that showed

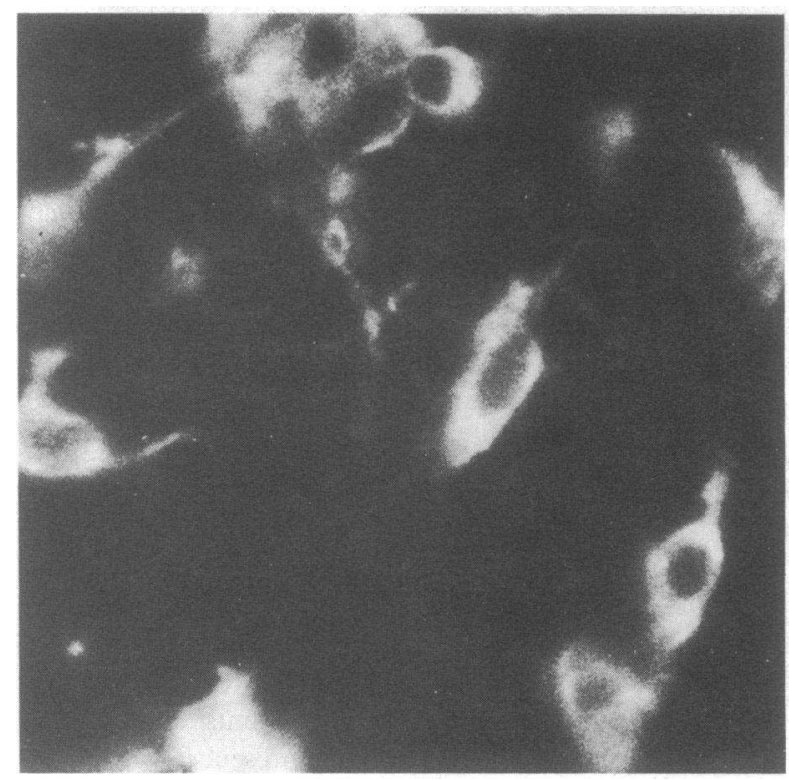

Figure 7. Frozen section from a hyperplastic MG thymus labeled with the anti-HLA-DR MAb (revealed by GAMIgG2b/FITC). In the hyperplastic thymus, HLA-DR molecules are well-expressed by epithelial reticular cells. $\times 500$. 
abnormally high levels of thymulin (39) and thymopoietin (40) in MG. The thymic specificity of the increase in hormone serum level was evidenced by the disappearance of thymulin from thymomatous and myasthenic sera after thymectomy. Furthermore, we confirmed the previous reports by Chollet et al. (41) and Kirkpatrick et al. (42) who found increased thymic hormone blood levels in two thymomas not associated with MG.

The consequences of the augmentation of thymic hormone production must be discussed in terms of the immune status of myasthenic patients. Considering the stimulatory effect of thymic hormones on $\mathrm{T}$ helper cells (see reviews in references 43 and 44), it may be hypothesized that high levels of these hormones may be indirectly involved in the autoantibody synthesis present in many of these patients.

Our data open the possibility of using antithymic hormone antibodies as specific markers of epithelial cells concomitantly with antikeratin antibodies for the differential diagnosis of thymoma and other undifferentiated metastatic tumors. In two cases the thymic origin of the neoplastic cells could not be ascertained either by light or by electron microscopy. In these cases, the use of antikeratin antibodies currently used to distinguish between thymic lymphomas and thymomas with predominant lymphocytic populations (6) did not provide sufficiently clearcut data to positively identify thymomas from other tumors of epithelial origin. Their thymic epithelial cell nature was definitely established by the binding of antithymulin and antithymosin $\alpha 1$ antibodies, two antibodies previously shown to bind selectively to the thymic epithelial cells $(11-14)$ but not to any other normal or neoplastic tissue so far tested. Although the thymic specificity of thymosin $\alpha 1$ has recently been questioned by Haritos et al. (45), who demonstrated by radioimmunoassay the presence of prothymosin- $\alpha$ in several nonthymic tissues, to date the detection of the mature hormone as assessed by immunohistochemical means remains restricted to the thymus.

Our data clearly show that the thymomas examined in this study do not express the class II products of the MHC. The minority of cells labeled with the anti-DR (or anti-DC) antibody was keratin-negative, hence nonepithelial and not belonging to the malignant proliferation. Conversely, in hyperplastic and involuted myasthenic thymuses, HLA-DR and HLA-DC positive epithelial cells were distributed in patterns similar to those found in normal thymuses as already described by Rouse et al. (46) and Natali et al. (47) but differing from a recent finding by Bofill et al. (48), who did not find HLA-DR-positive cells in the medulla of hyperplastic thymic lobules. This absence of expression of MHC products by thymomatous epithelial cells is restricted to class II molecules, since HLA-ABC antigens were strongly detected in all cases studied.

The basis for this lack of class II molecules (as assessed by IF and immunoblot analysis) on thymomatous epithelial cells is not clearly understood. It may be hypothesized that it is simply due to the malignantly altered nature of the epithelial cell which does not permit the expression of the class II molecules. Alternatively, the absence of DR and DC antigens on the thymomatous epithelial cells could be explained by the exclusive development of malignant cells from a subpopulation of $D R / D C$ negative epithelial cells. Although, to date, there is not any direct proof arguing for one of these hypotheses, it is interesting in this context to note that primary cultures of normal human thymic epithelial cells have also been shown to be DR-negative (49) while producing increasing amounts of thymulin as a function of the time in culture (50), a finding that argues in favor of a possible dissociation in the expression of class II molecules and thymic hormones.

The immunological consequences of the absence of class II expression during thymic differentiation events are difficult to evaluate in relatively old patients, like those studied here, whose lymphocytes have already undergone full $\mathrm{T}$ cell maturation. It remains, however, that these data render unlikely the role of HLA-DR/DC ${ }^{+}$cells in the initiation of the tumors. Conversely, the role of thymic hormones in this initiation, in conjunction with other signals or stimuli, could be envisaged since thymic hormones promote $\mathrm{T}$ cell differentiation and proliferation.

\section{Acknowledgments}

We thank Drs. J. Brochier, R. Bono, B. Malissen, and M. Fellous for providing monoclonal antibodies, Dr. A. L. Goldstein for the gift of antithymosin $\alpha 1$ antibody, Dr. C. Stähli for providing synthetic thymosin $\alpha 1$, Dr. E. Morel for titrating the antiacetylcholine receptor antibodies, M. C. Gagnerault, C. Rieumailhol, D. Brugerolles, and B. Olivier for their skillful technical assistance, and J. Jacobson for reviewing the manuscript.

\section{References}

1. Rosai, J., and G. D. Levine. 1976. Tumors of the thymus. In Armed Forces Institute of Pathology. Washington, DC.

2. Levine, G. D., and J. Rosai. 1978. Thymic hyperplasia and neoplasia: a review of current concepts. Hum. Pathol. 9:495-515.

3. Holmes-Sellors, T., A. C. Thackray, and A. D. Thomson. 1967. Tumours of the thymus. A review of 88 operation cases. Thorax. 22: 193-220.

4. Verley, J. M., and K. H. Hollmann. 1984. Thymoma. A comparative study of clinical stages and histology of 200 cases. Cancer (Phila.). In press.

5. Löning, T., J. Caselitz, and H. F. Otto. 1981. The epithelial framework of the thymus in normal and pathological conditions. Virchows Arch. A Pathol. Anat. Histol. 393:7-20.

6. Battifora, H., T. T. Sun, R. M. Bahu, and S. Rao. 1980. The use of antikeratin antiserum as a diagnostic tool: thymoma versus lymphoma. Hum. Pathol. 11:635-641.

7. Bach, J. F. 1979. Thymic hormones. J. Immunopharmacol. 1: 277-310.

8. Bach, J. F., M. Dardenne, J. M. Pléau, and J. Rosa. 1977. Biochemical characterization of a serum thymic hormone. Nature (Lond.). 266:55-56.

9. Goldstein, A. L., T. L. K. Low, M. McAdoo, J. McLure, G. B. Thurman, J. I. Rossio, C. Y. La, D. Chang, S. Wang, C. Harvey, A. H. Ramel, and J. Meienhofer. 1977. Thymosin $\alpha 1$ : isolation and sequence analysis of an immunologically active thymic polypeptide. Proc. Natl. Acad. Sci. USA. 74:725-729.

10. Schlesinger, D. H., and G. Goldstein. 1975. The aminoacid sequence of thymopoietin II. Cell. 5:361-364.

11. Monier, J. C., M. Dardenne, J. M. Pléau, D. Schmitt, P. Deschaux, and J. F. Bach. 1980. Characterization of the facteur thymique sérique (FTS) in the thymus. I. Fixation of anti-FTS antibodies on thymic reticulo-epithelial cells. Clin. Exp. Immunol. 42:470-476.

12. Jambon, B., P. Montagne, M. C. Bene, M. P. Brayes, G. Faure, and J. Duheille. 1981. Immunohistologic localization of "Facteur Thymique Sérique (FTS)" in human thymic epithelium. J. Immunol. 127: 2055-2059.

13. Savino, W., M. Dardenne, M. Papiernik, and J. F. Bach. 1982. Thymic hormone containing cells. Characterization and localization of serum thymic factor in young mouse thymus studied by monoclonal antibodies. J. Exp. Med. 156:628-634.

14. Dalakas, M., W. K. Engel, J. E. McLure, A. L. Goldstein, and V. Askanas. 1981. Immunocytochemical localization of thymosin $\alpha 1$ in 
thymic epithelial cells of normal and myasthenia gravis patients and in thymic cultures. J. Neurol. Sci. 50:239-247.

15. Hirokawa, K., J. E. McLure, and A. L. Goldstein. 1982. Age related changes in localization of thymosin in the human thymus. Thymus. 4:19-29.

16. Goldstein, G. 1975. The isolation of thymopoietin (thymin). Ann. NY Acad. Sci. 249:177-183.

17. Haynes, B. F., K. Shimisu, and G. E. Eisenbarth. 1983. Identification of human and rodent thymic epithelium using tetanus toxin and monoclonal antibody A2B5. J. Clin. Invest. 71:9-14.

18. Schmitt, D., J. C. Monier, M. Dardenne, J. M. Pléau, and J. F. Bach. 1982. Location of FTS (Facteur Thymique Sérique) in the thymus of normal and autoimmune mice. Thymus. 4:221-231.

19. Schmitt, D., J. C. Monier, M. Dardenne, J. M. Pléau, P. Deschaux, and J. F. Bach. 1980. Cytoplasmic localization of FTS (Facteur Thymique Sérique) in thymic epithelial cells. An immunoelectron, microscopal study. Thymus. 2:177-186.

20. Auger, C., J. C. Monier, M. Dardenne, J. M. Pléau, and J. F. Bach. 1982. Identification of FTS (Facteur Thymique Sérique) on thymus ultrathin sections using monoclonal antibodies. Immunol. Letters. 5: 213-216.

21. Rouse, R. V., W. Van Ewijk, P. P. Jones, and I. L. Weissman. 1979. Expression of MHC antigens by mouse thymic dendritic cells. $J$. Immunol. 122:2508-2512.

22. Van Ewijk, W., R. V. Rouse, and I. L. Weissman. 1980. Immunoelectron microscopic identification of I-A and $\mathrm{H}-2 \mathrm{~K}$ bearing cells. J. Histochem. Cytochem. 28:1089-1099.

23. Janossy, G., J. A. Thomas, F. J. Bollum, S. Granger, G. Pizzolo, K. F. Bradstock, L. Wong, A. MacMichael, K. Ganeshaguru, and A. V. Bradstock. 1980. The human thymic microenvironment: an immunohistologic study. J. Immunol. 125:202-212.

24. Viac, J., A. Reano, J. Brochier, M. J. Staquet, and J. Thivolet. 1983. Reactivity pattern of a monoclonal antikeratin antibody (KL1). J. Invest. Dermatol. 81:351-354.

25. Hansen, J. A., P. J. Mastin, and R. C. Nowinski. 1980. Monoclonal antibodies identifying a novel $\mathrm{T}$-cell antigen and Ia antigens of human lymphocytes. Immunogenetics. 10:247-260.

26. Bono, R., F. Hyafil, J. Kalil, V. Koblar, J. Wiels, E. Wollman, C. Mawas, and M. Fellous. 1979. Monoclonal antibodies against HLADRW antigens. Transpl. Clin. Immunol. 11:109-114.

27. Lampson, L. A., and R. Levy. 1980. Two populations of Ia-like molecules of human B cell line. J. Immunol. 125:293-296.

28. Chen, Y., R. L. Evans, M. S. Pollack, L. L. Lanier, J. H. Philips, C. Rousso, N. L. Warner, and F. M. Brodsky. 1984. Characterization and expression of the HLA-DC antigens defined by anti-Leu 10. Hum. Immunol. 10:221-235.

29. Brodsky, F. M. 1984. A matrix approach to human class II histocompatibility antigens: reactions of four monoclonal antibodies with the products of nine haplotypes. Immunogenetics. 19:179-194.

30. Rebai, N., and B. Malissen. 1983. Structural and genetic analysis of HLA class I molecules using monoclonal xenoantibodies. Tissue Antigens. 22:107-117.

31. Crevat, D., J. Kalil, and M. Fellous. 1983. Présence de deux épitopes sur la $\beta 2$ microglobuline humaine définis par des anticorps monoclonaux. Ann. Inst. Pasteur. (Paris). 134C:31-41.

32. McLure, J. E., N. Lameris, D. W. Wara, and A. L. Goldstein.
1981. Immunochemical studies on thymosin: radioimmunoassay of thymosin $\alpha 1$. J. Immunol. 128:368-375.

33. Berrih, S., W. Savino, M. Azoulay, M. Dardenne, and J. F. Bach. 1984. Production of anti-thymulin (FTS) monoclonal antibodies by immunization against human thymic epithelial cells. J. Histochem. Cytochem. 32:432-438.

34. Laemmli, V. K. 1970. Cleavage of structural proteins during the assembly of the head of bacteriophage T4. Nature (Lond.). 277:680-684.

35. Dardenne, M., and J. F. Bach. 1975. The sheep cell rosette assay for the evaluation of thymic hormones. In Biological Activity of Thymic Hormones. D. Van Bekkum, editor. Kooyker Scientific Pub., Leiden. 235-243.

36. Garaci, E., R. Ronchetti, V. Del Gobbio, G. Trannutoti, C. Rinaldi-Garaci, and C. Imperato. 1978. Decreased serum thymic activity in asthmatic children. J. Allergy Clin. Immunol. 62:357-362.

37. Franceschi, C., F. Licastro, M. Chiricolo, F. Bonetti, M. Zanetti, N. Fabris, E. Mocchegidin, M. Pia-Fantini, B. Paolucci, and M. Masi. 1981. Deficiency of autologous mixed lymphocyte reactions and serum thymic factor level in Down's syndrome. J. Immunol. 126:2161-2164.

38. Iwata, T., G. S. Incefy, R. A. Good, S. Cunningham-Rundles, M. Dardenne, N. Kapoor, D. Kirkpatrick, and R. J. O'Reilly. 1983. Circulating thymic hormone levels in severe combined immunodeficiency. Clin. Exp. Immunol. 53:1-9.

39. Bach, J. F., M. Dardenne, M. Papiernik, A. Barrois, P. Levasseur, and $H$. Le Brigand. 1972. Evidence for a serum factor produced by the human thymus. Lancet. I:1056-1058.

40. Twomey, J. J., V. M. Lewis, B. M. Patten, G. Goldstein, and R. A. Good. 1979. Myasthenia gravis, thymectomy and serum thymic hormone activity. Am. J. Med. 66:639-643.

41. Chollet, P., R. Plagne, Y. Fonck, J. Chassage, G. Betail, M. Dardenne, and J. F. Bach. 1981. Thymoma with hypersecretion of thymic hormone. Thymus. 3:321-334.

42. Kirkpatrick, H., E. Lynn, and S. Greenberg. 1978. Plasma thymic hormone activity in patients with chronic mucocutaneous candidiasis. Clin. Exp. Immunol. 34:311-317.

43. Goldstein, A., T. L. K. Low, M. M. Zatz, N. R. Hall, and P. H. Naylor. 1983. Thymosins. Clinics Immunol. Allergy. 3:119-132.

44. Bach, J. F. 1983. Thymulin (FTS-Zn). Clinics Immunol. Allergy. 3:132-156.

45. Haritos, A. A., G. J. Goodall, and B. L. Horecker. 1984. Distribution of prothymosin $\alpha$ in rat tissues. Proc. Natl. Acad. Sci. USA. 81: 1391-1393.

46. Rouse, R. V., P. Parham, F. C. Grumet, and I. L. Weissman. 1982. Expression of HLA antigens by human thymic epithelial cells. Hum. Immunol. 5:21-34.

47. Natali, P. G., O. Segatto, S. Ferrone, R. Tosi, and G. Corte. 1984. Differential tissue distribution and ontogeny of DC.1 and HLA-DR antigens. Immunogenetics. 19:109-116.

48. Bofill, M., Trejdosiewicz, A. Goodall, N. Willcox, J. Newson Davis, and G. Janossy. 1983. Immunohistology of thymus in myasthenia gravis. Spring Meeting. Brit. Soc. Immunol. 45. (Abstr.)

49. Sun, T. T., P. Bonitz, and W. H. Burns. 1984. Cell culture of mammalian thymic epithelial cells: growth, structural and antigenic properties. Cell. Immunol. 83:1-13.

50. Cohen, S., S. Berrih, M. Dardenne, and J. F. Bach. 1983. Régulation in vitro de la sécrétion de thymuline par les cellules épithéliales thymiques humaines. C.R. Acad. Sci. (Paris). 297:63-65. 